\title{
Maladaptive schemas and psychological well-being in premenopausal and postmenopausal women
}

\author{
Farahnaz Hashemipoor, Forough Jafari, Rozita Zabihi \\ Department of Psychology, Islamic Azad University, Islamshahr Branch, Iran
}

\begin{abstract}
Introduction: Menopause as an important event during women's life has serious effects on their mental health. This study was carried out to investigate the relationship between early maladaptive schemas and psychological well-being in postmenopausal and premenopausal women.

Material and methods: The research method was descriptive-correlative. The population of this study included menopausal and premenopausal women who were referred to five community centers in district 9 in Tehran in the spring of 2018. The statistical sample comprised 282 (45-55 years old) women who were divided into 142 postmenopausal and 140 premenopausal women selected through accessible sampling. In this study two questionnaires were filled out by sample groups: the Young Schema Questionnaire (2003) and Ryff's Scales of Psychological Well-being (1989) were applied. Spearman correlation test and multiple regression analysis were employed in order to analyze hypotheses of this study.

Results: The results indicated that the collection of schemas which were aimed at predicting psychological well-being in menopausal and premenopausal women were different $(p \leq 0.01)$. In premenopausal women isolationism, vulnerability, and subjugation schemas, and in postmenopausal women defectiveness/shame, isolationism, dependency, self-control, and approval-seeking schemas predicted psychological well-being.

Conclusions: Menopause can activate some passive schemas, and psychologists through making women aware of these change and using appropriate interventions can prevent a decrease well-being in them.
\end{abstract}

Key words: early maladaptive schemas, psychological well-being, premenopausal women, postmenopausal women.

\section{Introduction}

Menopause is an important and common old age phenomenon in women's life which causes a transition into a new biological state, and leads to a gradual decline in fertility [1]. The symptoms and side effects of menopause are due to a decrease of sexual hormones, personality factors and women's attitude towards menopause, and social and environmental factors [2]. Although natural menopause does not cause any significant cognitive changes in women [3], from a psychological perspective, the meaning of life, self-efficacy beliefs, and the image of the body play significant roles in the quality of life among postmenopausal women [4]. In Iran, a part of women's values includes physical attraction, fertility, and serenity in dealing with adolescence, which may be undermined because of temporal fluctuations [5]. In this regard the results of research by Jafari, Hadizadeh, Zabihi and Ganji [6] signified that quality of life, vitality, and mental health in the postmenopausal period in Iranian women decreased whereas there was an increase in anxiety and depression.

Although menopause is a natural and physiologic phenomenon, the global phenomenon of population ageing and following that the increase in the number of postmenopausal women caused health and women's hygiene in premenopause to become an important issue [7]. Ozkan, Alta and Zencir [8] believe that life expectancy has increased in women all over the world, and in most countries women who turn 50 are expected to live 30 to 40 years more, therefore spending more time in their menopausal period.

Thus, careful attention to factors affecting psychological well-being in women before and after the experience of menopause are crucial, in that they contribute to the identification of side effects of menopause, enhance mental health, and prevent psychological disorders. Researchers also believe that perception of menopausal transition has a crucial effect on mental health and symptoms' frequency and intensity in women [9]. 
Positive psychologists believe that mental health encompasses lack of disease and inability as well as the feeling of happiness and well-being [10].

The feeling of well-being means a person's overall evaluation of life, which is achieved by means of personal goals and the extent of their attainment [11]. Psychological well-being consists of six factors of selfacceptance, sympathy, autonomy, purpose in life (having goals in life and giving meaning to them), personal growth, and environmental mastery [12].

Those who benefit from psychological well-being endeavor to enhance their abilities, have effective interpersonal communication, and minimize the conflicts in their life [13]. Psychological well-being is a situational variable; that is to say, in different situations such as workplace, family, and life diverse definitions have been given about it [14]. Hence menopause as an important biological, mental, and social experience can bring about remarkable changes in psychological well-being of women.

One of the most important factors that can influence psychological well-being in women is early maladaptive schemas. Early maladaptive schemas are patterns or pervasive and deep themes which consist of memories, emotions, bodily sensations, and cognitions, and are associated with destructive aspects of childhood experiences, and recur in different patterns in an organized manner throughout the whole years of adulthood and are dysfunctional to a significant degree [15].

Young et al. [16] introduced five domains for schemas - Dimension one: disconnection and rejection, abandonment and instability, mistrust and abuse, emotional deprivation, defectiveness and shame, social isolation and alienation. Domain two: impaired autonomy and performance domain, dependence and incompetence, vulnerability to harm and illness, undeveloped self, enmeshment, failure. Domain three: impaired limits, entitlement and grandiosity, insufficient self-control/self-discipline. Domain four: other-directedness, subjugation, self-sacrifice, approval-seeking/ recognition-seeking. Domain five: hypervigilance and emotional inhibition, negativity/pessimism, unrelenting standards/hypercriticalness and punitiveness.

Beck [17] states that when schemas confront new stimuli, they screen, code, and evaluate the information based on their previous structure [18]. He also indicated that schemas may be inactive at times and after this period, as a result of the change in the type of inputs they receive from the environment, they quickly become active or go to the previous inactive state. According to the significant increase in anxiety and depression in postmenopausal women and considering these disorders which originate from maladaptive schemas, there is a possibility that diverse schemas are active in this period which were inactive before and some of the previous active schemas may become inactive due to changes in the situations. Therefore, it is expected that these changes in early maladaptive schemas can pre- dict psychological well-being in postmenopausal and premenopausal women.

According to the aforementioned statements, the purpose of this study to answer this question: "What are the differences among maladaptive schemas with psychological well-being in postmenopausal and premenopausal women?".

\section{Material and methods}

The research method was descriptive-correlative. All procedures of this research were confirmed by ethical committee of IAU, Islamshahr Branch, Islamshahr, Iran (references number: 2018/489). The population of this study comprised menopausal and premenopausal women (45-55 years old) who lived in the $9^{\text {th }}$ district in Tehran in the spring of 2018. Since Loehlin (1992) concluded that for this class of research with two or four factors [19], the researcher should plan to collect a minimum of 100 to 200 cases, the statistical sample was 300 women (inclusion criteria: married, having children, natural menopause in menopausal women, having at least diploma educations and exclusion criteria: divorced, having serious physical or mental problems, drug abuse). The sample was selected through stratified cluster sampling: in the first cluster, from 22 districts of Tehran one district was selected randomly and from 25 cultural-educational centers in the $9^{\text {th }}$ district, five centers were selected randomly then from each of these centers 60 women (30 menopausal and 30 premenopausal) were selected by announcing on the bulletin board and women who gave consent to participate in the research completed the questionnaires.

From the 300 questionnaires, 282 questionnaires which included 142 postmenopausal and 140 premenopausal women's questionnaires were returned and appropriately completed to be analyzed.

In order to collect data in addition to study variety of related texts in investigation area, two questionnaire has been used as well.

\section{Young Schema Questionnaire}

Young Schema Questionnaire - Short Form version has 90 items and the psychometrics of all 18 presented schemas by Young [20] were employed. The scale of this questionnaire is Likert and is categorized from 1 (completely incorrect about me) to 6 (completely correct about me). Divandari et al. [21] reported that Cronbach's $\alpha$ in 18 subscales of this questionnaire is $71-90 \%$. In this study final factors using Cronbach's $\alpha$ for subscales were $70-89 \%$.

\section{Ryff's Psychological Well-being Questionnaire}

Ryff's Psychological Well-being Scale (1989) has 84 questions. This questionnaire examines 6 main compo- 
nents of a psychological well-being model. The consistency coefficient of subscales of the main questionnaire were reported as follows by its creator: autonomy $76 \%$, mastery $90 \%$, personal growth $87 \%$, communication with others $91 \%$, purposeful life $90 \%$, self-acceptability $93 \%$. The reliability of the recovery method in subscales in a sample of 171 participants after six weeks was $81-85 \%$. In Iranian normalizing, the final coefficient in research by Zanjani Tabasi [22], using internal consistency (Cronbach's $\alpha$ coefficient), for all the psychological well-being test was $94 \%$ and in subscales was $63 \%$ to $89 \%$. The reliability of the questionnaire in this study was investigated using Cronbach's $\alpha$, which was more than $0 / 75$ for all subscales.

In analysis of the data Spearman's coefficient and multiple regression tests were employed.

\section{Findings}

The mean psychological well-being in postmenopausal women is 291.72 and in premenopausal women this variable equals 292.67 .

\section{Hypothesis of the study}

There is a difference between early maladaptive schemas and psychological well-being in postmenopausal and premenopausal women.

In order to investigate this hypothesis multiple regression was employed. Consequently, in the regression equation only those schemas which have a significant correlation with the base variable are included (Table 1).

Enmeshment, self-sacrifice, unrelenting standards, and entitlement variables were excluded from the regression equation as they did not have significant correlation with psychological well-being.
The correlation coefficient $(R)$ is reported to be 0.67 $(p \leq 0.01)$ and $46 \%$ change in the score of psychological well-being in postmenopausal women, which is achieved using 14 interactions of maladaptive schemas, is predicted.

Investigation of the value of $\beta$ indicated that the effects of isolation, defectiveness, dependence, self-control, and approval-seeking variables were significant for wellbeing (Table 2).

In premenopausal women the variables of selfsacrifice and entitlement did not enter the regression equation due to the fact that they lacked a significant correlation with psychological well-being.

The reported correlation coefficient $(R)$ is 0.65 $(p \leq 0.01)$ and $42 \%$ change in the score of psychological well-being in premenopausal women using the interaction of 15 maladaptive schemas is predicted.

Separate investigation of the values of beta indicated that only the effect of isolation, vulnerability and subjugation is significant for well-being, and the rest of the schemas do not have a significant effect on the prediction of psychological well-being.

In sum, according to the results from multiple regression, all the schemas which have a relationship with psychological well-being are different in postmenopausal and premenopausal women. In premenopausal women, vulnerability, isolation and subjugation schemas have an influence on psychological well-being and in postmenopausal women, defective, self-control, dependence, self-approval, and isolation schemas have an influence on psychological well-being.

\section{Discussion and Conclusions}

According to the results from multiple regression, it was found that all the schemas which have a relation-

Table 1. Regression coefficients for predictors of psychological well-being in postmenopausal women

\begin{tabular}{lcccc}
\hline Independent variable & Value of B & $\beta$ & Value of $t$ & -1.23 \\
\hline Emotional deprivation & -0.13 & -0.13 & 0.22 \\
\hline Abandonment & 0.63 & 0.007 & 0.95 \\
\hline Mistrust & 0.58 & 0.08 & 0.70 & 0.48 \\
\hline Isolation & -2.74 & 0.24 & 1.77 & -4.31 \\
\hline Defectiveness & 0.16 & -0.54 & 0.03 & 0.0001 \\
\hline Failure & -0.01 & 0.003 & -2.51 \\
\hline Dependence & -0.05 & -0.28 & 0.37 & 0.97 \\
\hline Vulnerability & 0.27 & 0.05 & -0.93 \\
\hline Subjugation & -0.74 & -0.11 & 1.31 \\
\hline Emotional inhibition & 0.82 & 0.14 & -4.35 \\
\hline Self-control & -3.07 & -0.53 & 1.87 \\
\hline Approval-seeking & 1.28 & 0.24 & 1.35 \\
\hline Negativity & 1.05 & 0.19 & 0.70 \\
\hline Punitiveness & 0.22 & 0.03 & 0.39 \\
\hline Significant level of $F=0.0001, F=4.33, R=0.65, R^{2}=0.42$ & 0.03 & 0.19 \\
\hline
\end{tabular}


Table 2. Regression coefficients for predictors of psychological well-being in premenopausal women

\begin{tabular}{|c|c|c|c|c|}
\hline Independent variable & Value of $B$ & $\beta$ & Value of $t$ & $p$-value \\
\hline Emotional deprivation & -0.13 & -0.02 & -0.16 & 0.87 \\
\hline Abandonment & 0.63 & 0.11 & 0.58 & 0.56 \\
\hline Mistrust & 0.58 & -0.09 & -0.45 & 0.64 \\
\hline Isolation & -2.74 & -0.33 & -2.70 & 0.03 \\
\hline Defectiveness & 0.16 & 0.02 & 0.14 & 0.88 \\
\hline Failure & -0.01 & -0.003 & -0.01 & 0.98 \\
\hline Dependence & -0.05 & -0.007 & -0.04 & 0.96 \\
\hline Vulnerability & -3.42 & -0.54 & -3.43 & 0.001 \\
\hline Subjugation & -1.72 & -0.25 & -1.71 & 0.05 \\
\hline Emotional prohibition & 1.37 & 0.21 & 1.60 & 0.11 \\
\hline Unrelenting standards & 0.91 & 0.13 & 1.08 & 0.28 \\
\hline Self-control & -1.08 & 0.16 & 1.16 & 0.24 \\
\hline Approval-seeking & -0.79 & -0.15 & 1.07 & 0.28 \\
\hline Negativity & 0.41 & 0.07 & 0.38 & 0.70 \\
\hline Punitiveness & 0.79 & 0.12 & 1.08 & 0.28 \\
\hline
\end{tabular}

Table 3. Comparison of domains of schema in postmenopausal and premenopausal women

\begin{tabular}{lcc}
\hline Domain & Active schemas in postmenopausal women & Active schemas in premenopausal women \\
\hline Disconnection and rejection & Defectiveness - shame/isolation & Isolation \\
\hline Impaired autonomy and performance & Dependence/self-control & Vulnerability \\
\hline Other-directedness & Self-approval & Subjugation \\
\hline
\end{tabular}

ship with psychological well-being are different in postmenopausal and premenopausal women and based on the present results in Table 3 postmenopausal and premenopausal women have in common only the isolation schema.

According to the results, the effect and importance of schemas in different stages of life are not the same. Beck et al. [23] believe that previous negative happenings can have an impact on the shape of schemas which are coded in the memory and hence influence the interpretation of the new information. Symptoms during and after menopause activate some early maladaptive schemas and influence psychological well-being in women, which is why schemas are considered as frames which are shaped based on the reality or experience in order to help people to explain their experiences [24]. When maladaptive schemas are provoked, people experience a high level of intensive emotions which leads to instability and imbalance in the behavior of individuals which can decrease psychological wellbeing [25].

Vulnerability and subjugation schemas which in premenopausal women had a significant relationship with psychological well-being have no significant relationship in postmenopausal women. Considering the lack of significant relationship between vulnerability and psychological well-being after menopause, it can be assumed that vulnerability, which is an extreme fear of a disaster that is approaching and can occur at any moment, and it cannot be prevented [16], is experienced mostly by women before the age of 50 , who normally have teenagers and young children and face some growth issues of this stage of life (independence, avoiding parents, inappropriate emotions and instability). Since this research was carried out in April and May of 2018 and at that time an earthquake hit Tehran, most women were worried about losing their children and their own death in addition to general fear of an earthquake and about how their children are going to live their life. Since menopause will activate some illnesses and some health issues [1], it seems that direct confrontation with these changes will reduce their vulnerability and they can accept their current status nondisastrously.

An individual with the subjugation schema feels excessive surrendering of control to others. There are two forms of subjugation: A) subjugation of needs; B) subjugation of emotions [26].

It seems despite the fact that in Iranian culture in which a mother's role is defined as ignoring personal needs, positive emotional needs, and emotions, this schema can reduce psychological well-being in premenopausal women, whereas in post-menopause because of two reasons this negative effect can be reduced. First, 
subjugation which is regarded as a kind of positive reinforcement from others as a result of surrendering to their demands can be assumed to be a type of social support [27]. Second, menopause starts for a woman when she stops and reviews her beliefs about herself and her surrounding world, and a woman may move towards a direction that she desired but it was impractical [28]. Therefore by reevaluating available abilities and facilities followed by unmet needs, they enter the remaining time of their life and this endeavor can cause the subjugation schema to lose its power of negative effect on psychological well-being.

The schemas of defectiveness/shame, isolation, dependence, and self-control/approval-seeking are considered as the most important predictors of psychological well-being in postmenopausal women. According to the findings of Jafari et al. [5] concerning the increase in women's depression after menopause, and the fact that depression schemas are fundamental theories, on the condition that they present themselves as incapable, the world full of problems, and the future hopeless [26], and spiritual-mental variables such as depression and anxiety as a mediator for the effects of personal changes (such as cognition schemas) which can influence the quality of life [29], it can be argued that the experience of menopause activates depression schemas and has an impact on psychological well-being.

The defectiveness/shame schema is a predictor of psychological well-being. This schema refers to the feeling that every individual is defective, inappropriate, inferior and worthless in their most important personality traits, and feels embarrassed in relation to internal defects and faults [25].

In many cultures, women see their popularity in being from a female gender and their role in having children, giving birth [30], and beauty [4]. Therefore, the experience of infertility after menopause is regarded as a failure for women and creates the feeling that they are not a complete woman. The feelings related to these losses include sadness, inferiority, loneliness, fatigue, frustration, and fear [9]. Following the experience of menopause and creating a feeling in women that their beauty is on the decline, defectiveness schemas will be activated. In a study carried out by Stiles [31], early maladaptive schemas of emotional deprivation and defectiveness were predictors of low intimate and romantic relationship between couples [32], which influence psychological well-being indirectly. According to the findings, the relationship of isolation and the psychological well-being schema in premenopausal women is positive, which indicates that postmenopausal women experience a lower level of psychological wellbeing as isolation increases, whereas postmenopausal women can experience a higher level of psychological well-being as isolation increases. Individuals who have an isolation schema believe that they are different from others and do not have a sense of belonging to the group and have isolation and abandonment [16]. Yung believed that by middle age problems related to adapting to life have been normally solved, and issues concerning marriage, job, and society have reached relative stability. He also believed that the first half of life is devoted to the real and objective world (hence isolation is considered an unexpected feature in this period), while the second half of life should be devoted to the internal and mental world which were ignored previously. In other words, the perspective of personality should change from extroversion to introversion and the interests of individuals should change from physical and materialistic issues to spiritual, philosophical, and intuitive [33].

Individuals who have the dependence schema believe that they cannot fulfill their daily responsibilities to an acceptable level without significant help from others and consequently get frustrated [26]. Therefore, postmenopausal women based on their life experiences, age, and family and society's expectation of them, if they believe that they are incompetent and cannot do their daily task independently, in fact they consider themselves incompetent in environmental mastery and autonomy and their psychological well-being will be influenced.

The insufficient self-control schema and psychological well-being in postmenopausal women have a significant relationship. Individuals who have self-control schema lack two qualities: 1 . Self-control means the ability to control emotions and motions, 2. Self-discipline means the ability to tolerate illness and failure until the task is done [34]. By the increase in menopause side effects, psychosomatic diseases, and its consequent mood and emotional changes, postmenopausal women get negative experiences from inability to control their experiences. Researcher believe that depression, anxiety, excitability, reduction in concentration and forgetfulness are related to menopause [35]. Since postmenopausal women are looked upon as experienced individuals who have young teenagers and teens, inability to control motions and emotional reaction and inability to accomplish their tasks can influence autonomy, environmental mastery and purposefulness, which are the most important components of psychological well-being.

The approval-seeking schema is also considered one of the predictors of psychological well-being in postmenopausal women. These individuals pay a lot of attention to seeking and getting approval from others $[16,34]$. It seems with the decrease in the attraction and abilities of postmenopausal women and reduction of self-confidence, the need to be approved, respected, and honored by others increases; therefore those who seek approval and attention have a higher level of psychological well-being. 
The limitations of this study may include the following: since women who have more negative attitudes towards menopause report more menopausal symptoms [3], having insufficient information about their attitudes before menopause can affect the results. Cultural, social and economic diversities as factors affecting well-being were not considered in this research. This study was performed on married women who have children, which limits the possibility to generalize about single or married people without children. Since the findings of this study are limited to a statistical sample in Tehran, making generalizations about other cities is limited as well.

It is suggested that specialized workshops will be held in order to inform advisors about the features, needs, and effective schemas for psychological well-being of postmenopausal women. It is suggested that in order to reduce the marital conflicts after menopause, some courses should be held for their husbands and some information be given about schemas and their effects on conjugal relations and preventive measure be taken. Holding group therapy sessions for postmenopausal women and familiarization sessions with physical and psychological procedures in menopause for premenopausal women can reduce its negative side effects. Longitudinal study of active psychological schemas in women from premenopausal to postmenopausal periods and through time and also comparing single and married female individuals can have helpful implications.

\section{Disclosure}

The authors report no conflict of interest.

\section{References}

1. Perez JA, Garcia FC, Palacios S, Perez M. Epidemiology of risk factor and symptoms associated with menopause in Spanish women. Maturities 2006; 62: 30-36

2. Jami AZ, Bizheh N, Hashemijavaheri AA. The effect of aerobic exercise on menopausal symptoms and quality of life in non-athlete postmenopausal women. J Urmia Nurs Midwifery Fac 2014; 12: 173-182.

3. Bielawska-Batorowicz E. The psychology of the menopause: the experiences during the transition and individual conceptualization of menopause. In: CJH Martin et al. (eds.). Nutrition and diet in menopause. Springer Science + Business Media, New York 2013; 333-345.

4. Jafary F, Farahbakhsh K, Shafiabadi A, Delavar A. Quality of life and menopause: developing a theoretical model based on meaning in life, selfefficacy beliefs, and body image. Aging Ment Health 2011; 15: 630-637.

5. Jafari F, Farahbakhsh K, Shafiabadi A, Delavar A. Quality of life and menopause: realization of multifactorial health. J Women Law Develop 2010; 4: 55-79.

6. Jafari F, Hadizade M, Zabihi R, Ganji K. The comparison of anxiety, depression and quality of life between pre-menopausal women. Climacteric 2014; 17: 1-6.

7. Im EO, Ko Y, Chee E, Chee W. Cluster analysis of midlife women's sleeprelated symptoms: racial/ethnic difference. Menopause 2015; 22: 1182-1189.

8. Ozkan S, Alataş ES, Zencir M. Women's quality of life in the premenopausal and postmenopausal periods. Qual Life Res 2005; 14: 795-801.
9. Ambroziak E, Bielawska-Batorowicz E. Can the intensity of menopausal symptoms be modified? The pilot study of the effects of an intervention programme designed for 48-54-year-old women. Menopause Rev 2011; 10: 58-62.

10. Hatamluee Sadabadi M, Hashemi Nosratabad T. Comparing psychological well-being and marital satisfaction in fertile and infertile women of Tabriz health psychology. Health Psychol 2012; 1: 20-31.

11. Ryff CD. Psychological well-being in adult life. Curr Direct Psychol Sci 1995; 4: 99-104.

12. Ryff $C D$. Happiness is everything, or is it? Explorations on the meaning of psychological well-being. J Pers Soc Psychol 1989; 57: 1069-1081.

13. Mikaeeli MF. Investigating the status of psychological well-being of B.A student of Urumieh university. Ofogh Danesh Quarterly 2010; 16: 24-37.

14. Yosefi M, Khayatan F. Comparison of happiness, psychology well-being and job perfectionism among women nurses of different sections of hospitals in Isfahan at 2014. Sci J Hamadan Nurse Midwifery 2015; 23 : 52-62.

15. Nazari F, Kakavand A, Mashhadi Farahani M. The relationships between early maladaptive schemas and mothers parenting styles and children's external disorders. Applied Psychol 2015; 9: 115-135.

16. Young JE, Klosko JS, Weishaar ME. Schema therapy: A practitioner's guide. Arjmand, Persian, Tehran 2011.

17. Beck AT. Cognitive therapy and the emotional disorders. International Universities Press, New York 1976.

18. Sobhi Ghramaleki N, Poorabdol S, Abbasi M, et al. Effectiveness of group schema therapy on balancing early maladaptive schemas in harassed students. Res Edu Syst 2014; 9: 7-30.

19. Loehlin JC. Latent variable models: An introduction to factor, path, and structural analysis. Erlbaum, Hillsdale, NJ 1992.

20. Young JE, Brown G. Young Schema Questionnaire-L3a. Cognitive Therapy, Center of New York, New York 2003.

21. Divandari H, Ahi A, Akbari H, Mahdian H. Short form of early Schema Scale Questionnaire: A study of psychometric properties and factor structure among students. Educ Res J 2009; 5: 133-103.

22. Zanjani Tabasi R. Development and normalization of psychological wellbeing exams [master's thesis]. Tehran University 2014.

23. Beck AT, Rush AJ, Shaw BF, Emely G. Cognitive therapy. Guilford, New York 1979; 5-37

24. Rezaie Nasab F, Abasi I, Nairi GH, Barzegar M. Determination of basic maladaptive schemas in women with addictive relations. J Women Soc 2013; 4: 83-108.

25. Young J. Cognitive therapy of personality disorders, schema-focused approach. Agah, Tehran 1999.

26. Riso LP, Froman SE, Raouf M, et al. The long-term stability of early maladaptive schemas. Cogn Ther Res 2006; 30: 515-529.

27. Goudarz M, Foroughan M, Makarem A, Rashedi V. Relationship between social support and subjective well-being in older adults. Sija 2015; 10: 110-119.

28. King DE, Hunter MH, Harris JR. Dealing with the psychological and spiritual aspects of menopause: finding hope in the mid-life. Haworth Pastoral Press, Birmingham 2005.

29. Anderson IA, Eyler AA, Galuska DA, et al. Relationship of satisfaction with body size and trying to lose weight in a national sample of overweight and obese women aged 40 and older in the US. Prev Med 2002; 35: 390-396.

30. Fishbein EG. Women at midlife. Nurs Clin North Am 1992; 27: 951-957.

31. Stiles O. Early maladaptive schemas and intimacy in Young adults' romantic relationship [dissertation]. Alliant International University, Los Angeles 2004.

32. Haghparast $\mathrm{N}$. The role of early maladaptive schemas in predicting the psychological well-being of women exposed to divorce [master's thesis]. Mohaghegh Ardabili University 2013.

33. Schultz DP, Shcultz SA. Personality theories. Virayesh, Tehran 2016; 132133.

34. Salavati M, Yekehyazdandoost R. Schema therapy for clinical psychologist specialists. Danzheh, Tehran 2015; 72-81.

35. Laughlin D, Thorney Croft IH. Amenorrhea. Current obstetric and gynecologic diagnosis and treatment. 9th ed. McGraw Hill Companies, New York 2003; 991-1000. 